\title{
Expression of cyclooxygenase-2 in the mucosa of the gastroesophageal junction in patients with Barrett's oesophagus - the results of ablation therapy with argon plasma coagulation and laparoscopic Nissen fundoplication
}

\author{
Kazimierz Rembiasz, Marcin Migaczewski, Andrzej Budzyński, Anna Zub-Pokrowiecka, Marek Winiarski \\ $2^{\text {nd }}$ Department of Surgery UJ CM, Kraków, Poland
}

Videosurgery and other miniinvasive techniques 2010; 5 (2): 45-52 DOI: 10.5114/wiitm.2010.14203

\begin{abstract}
Introduction: Barrett's oesophagus (BE) is a result of replacement of the mucosa of the distal oesophagus by metaplastic columnar epithelium. The role of cyclooxygenase-2 (COX-2) and chronic inflammation in the progression of BE toward adenocarcinoma of the oesophagus is emphasized. Argon plasma coagulation (APC) allows for effective ablation of metaplastic mucosa. It is believed that effective suppression of gastric secretion with proton pump inhibitors (PPI) promotes squamous cell re-epithelialization and a decrease in expression of some biomarkers including COX-2. A similar effect can be achieved by the anti-reflux procedure.

Aim: To evaluate the usefulness of COX-2 expression in determining the risk of malignant transformation in patients with BE.

Material and methods: Patients from two out of three study groups underwent APC ablation of metaplastic mucosa combined with chronic PPI administration (group A) or laparoscopic Nissen fundoplication (group B). Controls (group K) were submitted only to PPI treatment. Expression of COX-2 was evaluated in fresh-frozen biopsy specimens obtained from the distal oesophagus in all 60 patients before and 12 months after treatment.

Results: Overexpression of COX-2 was found in 41 patients (68.3\%). The highest degree of COX-2 expression was documented in patients with dysplasia. After treatment overexpression of COX-2 was markedly reduced in patients from groups $A$ and $B$, which correlated well with histopathological findings. Controls did not show important changes in COX-2 expression.

Conclusions: Significant correlation of the degree of COX-2 overexpression with histopathological findings points to the possible use of this biomarker as a valuable indicator of the risk of malignant transformation in patients with $B E$.
\end{abstract}

Key words: Barrett's oesophagus, cyclooxygenase-2, argon plasma coagulation, laparoscopic Nissen fundoplication.

\section{Introduction}

Barrett's oesophagus (BE) is a result of replacement of the mucosa of the distal oesophagus by metaplastic columnar epithelium. According to former definitions it must involve at least $3 \mathrm{~cm}$ to fulfil the diagnostic criteria - so-called "classical" or "long segment" BE. Currently if the lesions are found in a segment shorter than $3 \mathrm{~cm}$ it is classified as "short segment" [1]. Cases of metaplasia presenting only as irregularities or patches of properly localized Z-line are referred to as "ultrashort" BE by some authors.

Barrett's oesophagus is believed to be an end stage of gastroesophageal reflux disease (GERD) as it 
is significantly more frequent among patients with reflux than in the general population. Even though it is generally recognized as a condition preceding development of adenocarcinoma of the gastroesophageal junction, the exact mechanisms of oncogenesis are not clear. Identification of those correlations seems crucial for selection of the group of patients at particular risk. Some increase (according to various authors ranging from $60 \%$ to $90 \%$ ) in the incidence of adenocarcinoma of the distal oesophagus associated with $B E$ has been observed [2, 3]. This could be attributed to higher incidence of GERD.

Progression of Barrett's metaplasia into oesophageal adenocarcinoma (EAC) is a result of chronic irritation of the mucosa by refluxate $[4,5]$. Even though $B E$ is reversible the chronic inflammation may promote progression of $B E$ into $E A C$ [6]. Pathogenesis of $B E$ is related to the character of the refluxate. A correlation between bile salt concentration and the degree of mucosal damage has been demonstrated [7].

It is nowadays clear that identification of the presence of metaplasia (gastric and/or intestinal) and the degree of dysplasia in the distal oesophagus is not sufficient for proper evaluation of the stage of the disease. The use of more precise markers of the risk of EAC is suggested. The value of more than 60 biomarkers is currently undergoing detailed studies; among them, cyclooxygenase-2 (COX-2) is believed to be one of the most promising $[8,9]$. It has been demonstrated that chronic irritation caused by exposure to bile salts results in enhanced expression of COX-2 in the metaplastic mucosa [10]. Numerous studies point to increased activity of COX-2 and prostaglandin $\mathrm{E}_{2}\left(\mathrm{PGE}_{2}\right)$ as factors promoting chronic inflammation and progression of carcinogenesis [7]. Prostaglandins - the main metabolites of the arachidonic acid cascade - seem to be potent factors in carcinogenesis modulating cellular adherence, the immune response, mitogenesis, cell proliferation, apoptosis and angiogenesis [7]. Overexpression of $\mathrm{COX}-2$ through mechanisms involving protein $\mathrm{Bcl}-2$ causes inhibition of apoptosis and concomitant enhancement of angiogenesis, which promotes progression of cancer [11, 13]. This is further supported by the observation of excessive expression of COX-2 in human neoplasms of the Gl tract, breast, lung, uterus and prostate [10]. The same overexpression was also found in patients with $\mathrm{BE}$, especially in cases of high-grade dysplasia and adenocarcinoma
$[10,16,17]$. It might be thus assumed that expression of COX-2 may be a useful marker of early stages of carcinogenesis [18].

Barrett's oesophagus is undoubtedly a serious complication of GERD, and thus might be considered a consequence of malfunction of the lower oesophageal sphincter (LES). The management of BE is based on the treatment of oesophageal reflux of gastroduodenal content. Treatment of Barrett's patients includes both methods applied typically in therapy of uncomplicated GERD and specific techniques $[19,20]$. This can be achieved by chronic use of medications decreasing gastric acid secretion mainly proton pump inhibitors (PPI). Similarly, antireflux surgery by restoration of the high pressure zone in the gastroesophageal junction decreases exposure of the distal oesophagus to irritating gastroduodenal refluxate [21]. Both methods are used in combination with various techniques of endoscopic mucosa ablation. All those procedures, including argon plasma coagulation (APC), promote re-epithelialization in the region of the GE junction [22].

There are no uniformly accepted standards of management of BE so far. It might be however assumed that effective treatment of GERD combined with ablation of metaplastic mucosa should decrease the risk of carcinogenesis. Accepting expression of COX-2 as a valuable marker of this process, it may prove useful in monitoring the treatment results.

\section{Aim}

The aim of the study was to evaluate the expression of COX-2 in the monitoring of treatment results of patients with $B E$. Patients were enrolled in three study groups: group $A$ - treated by APC ablation of BE combined with PPI; group B - APC ablation and antireflux procedure (LNF); and group K - PPI used as a sole method of management.

\section{Material and methods \\ Material}

The study group consisted of 60 patients with $\mathrm{BE}$ treated at the $2^{\text {nd }}$ Department of Surgery UJ CM in Krakow during 2005-2008. The inclusion criteria for this study comprised: endoscopic picture of BE confirmed by histologically proven glandular metaplasia in the distal oesophagus. There were 30 patients treated by APC ablation of metaplastic mucosa fol- 
lowed by administration of $80 \mathrm{mg}$ of pantoprazole (group A). In group B, consisting of 20 patients, APC ablation was combined with laparoscopic Nissen fundoplication (LNF). There were 10 controls (group K) who refused endoscopic ablation and were treated with pantoprazole ( $80 \mathrm{mg}$ per day) only.

There were 19 males (63.3\%) and 11 females (36.7\%) in group A. Mean age was 54.9 years. Group B consisted of 16 men (80\%) and 4 women (20\%). Mean age was 47.3 years. There were 7 male $(70 \%)$ patients and 3 females (30\%) in the control (K) group. Mean age was 50.1 years. The differences in sex ratio and age were statistically insignificant (NS). Detailed demographic data of the study subjects are presented in Table I.

\section{Methods}

All patients underwent gastroscopy with evaluation of the entire upper Gl tract to exclude other pathology of the oesophagus, stomach or duodenum. In all subjects with endoscopic suspicion of BE biopsy samples were obtained from the gastroesophageal junction for histological evaluation and assessment of the expression of COX-2. Throughout the entire study during all endoscopies biopsies were taken from all 4 quadrants of the gastroesophageal junction every one centimetre starting from the line of gastric folds to the Z-line (Figure 1).

For evaluation of the expression of COX-2 RNA was isolated with Trizol. After purification of RNA and quality testing the RT-PCR reaction was performed. CDNA synthesized in the process of reverse transcription served as a matrix for PCR gene amplification using specific primers. Electrophoresis on 1.5\% agarose gel with ethidium bromide was used for visualization and analysis of PCR products. Densitometric evaluation of electrophoretic bands was performed with Kodak Digital Science software.

Patients with confirmed BE who refused any invasive management were enrolled in a control group $(\mathrm{K})$ and received pantoprazole $80 \mathrm{mg}$ per day for 12 months (Figure 1).

The remaining 50 patients were subjected to endoscopic ablation of the mucosa of the distal oesophagus with APC. During each session of the endoscopic procedure 1-2 quadrants of the mucosa were destroyed. In the case of involvement of 3 or 4 segments endoscopic ablation of consecutive quad-

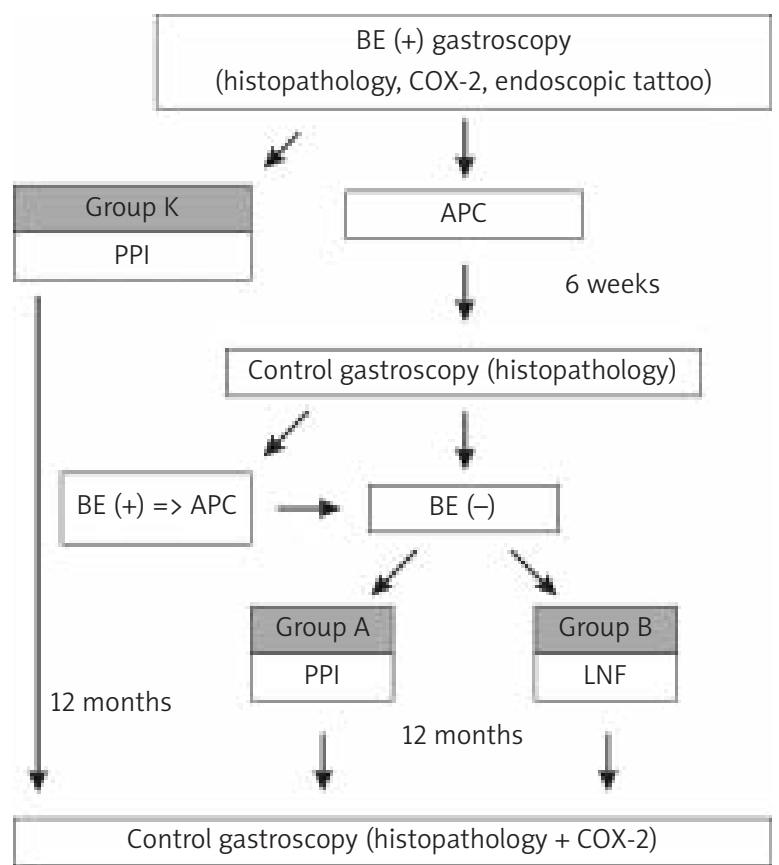

BE - Barrett's oesophagus, PPI - proton pump inhibitor, LNF - laparoscopic Nissen fundoplication, APC - argon plasma coagulation

Figure 1. Study design

Table I. Demographics of the study groups

\begin{tabular}{|c|c|c|c|c|c|c|c|c|}
\hline \multirow[t]{2}{*}{ Group } & \multirow[t]{2}{*}{$N$} & \multicolumn{2}{|c|}{ Sex } & \multicolumn{4}{|c|}{ Age [years] } & \multirow[t]{2}{*}{ Value of $p$} \\
\hline & & Female & Male & Mean & SD & Min. & Max. & \\
\hline \multirow[t]{2}{*}{ A } & \multirow[t]{2}{*}{30} & 11 & 19 & 54.9 & 10.9 & 26 & 72 & \multirow[t]{2}{*}{ NS } \\
\hline & & $36.7 \%$ & $63.3 \%$ & - & - & - & - & \\
\hline \multirow[t]{2}{*}{ B } & \multirow[t]{2}{*}{20} & 4 & 16 & 47.3 & 12.2 & 30 & 76 & \multirow[t]{2}{*}{ NS } \\
\hline & & $20.0 \%$ & $80.0 \%$ & - & - & - & - & \\
\hline K & 10 & 3 & 7 & 50.1 & 10.8 & 33 & 65 & NS \\
\hline
\end{tabular}


rants was performed after 4-6 weeks. After completion of endoscopic therapy follow-up endoscopy with biopsy was performed 6 weeks later. In the case of histologically documented failure the procedure was repeated until full eradication of metaplastic mucosa was achieved. Patients with a confirmed positive response to endoscopic treatment were assigned to two groups $-A$ and $B$.

Patients from group A refused anti-reflux surgery and were treated with pantoprazole $80 \mathrm{mg}$ per day for 12 months. Group B consisted of patients in whom endoscopic ablation was combined with laparoscopic Nissen fundoplication. Patients from all groups ( $\mathrm{A}, \mathrm{B}$ and $\mathrm{K}$ ) were submitted to follow-up endoscopy after 12 months.

\section{Results}

Before treatment, most patients presented with overexpression of COX-2 in biopsies from the gastroesophageal junction. Distribution of high, moderate and low overexpression of COX-2 was comparable in all study groups (Table II).

In group $\mathrm{A}$ - subjects treated with a combination of APC and PPI - increased expression of COX-2 was found in 21 out of 30 patients. High overexpression of COX-2 (+++) was present in 5 patients $(23.8 \%)$ with low-grade and moderate dysplasia. In 3 expression (14.3\%) was only moderately enhanced, while in 13 overexpression (61.9\%) was regarded as low (+). In the remaining 9 patients expression of COX-2 in biopsy specimens of metaplastic mucosa of the distal oesophagus was normal (Table II).

In group $\mathrm{B}$ - subjects treated with a combination of APC and LNF - overexpression of COX-2 was found in 13 out of 20 patients. In most of them overexpres- sion was low $(+)-8$ patients $(61.5 \%)$, or moderate $(++)-4$ patients (30.8\%). High overexpression of COX-2 (+++) was found in 1 patient $(7.7 \%)$ with lowgrade and moderate dysplasia (Table II).

In controls from group $\mathrm{K}$ - treated with PPI only overexpression of COX-2 was found in 7 out of 10 patients. The highest level of overexpression (+++) was found in 1 patient (14.2\%) with low-grade or moderate dysplasia. In 3 patients (42.9\%) overexpression was regarded as moderate $(++)$ and in the other $3(42.9 \%)$ as low (+). In 3 patients from the control group expression of COX-2 was normal (Table II).

In the initial evaluation of biopsy specimens the degree of COX-2 overexpression was related to the histological type of glandular metaplasia in all study groups. In 1 patient with gastric metaplasia (GM) the level of COX-2 overexpression was low (+). In the largest group of 42 patients with complete intestinal metaplasia (IM [+]) without dysplasia low (+) overexpression of COX-2 was most frequent (47.6\%). In $40.5 \%$ of patients from this group expression of COX-2 was normal. Only $12 \%$ of patients had moderate overexpression (++). Among 6 patients with incomplete intestinal metaplasia (IM [-]) without dysplasia $2(33.3 \%)$ had normal expression of COX-2, another $2(33.3 \%)$ had low (+) and the remaining 2 (33.3\%) a moderate $(++)$ level of overexpression of COX-2. In patients with IM (+) and low-grade or moderate dysplasia overexpression of COX-2 was high (+++) in $75 \%$ of patients and moderate $(++)$ in $25 \%$ of patients. Among 3 patients with IM (-) with low or moderate dysplasia each had a different level of COX-2 overexpression (Figure 2).

Second gastroscopy with biopsy of the gastroesophageal junction for histology and assessment of

Table II. The degree of overexpression of COX-2 in study groups before treatment

\begin{tabular}{|c|c|c|c|c|c|c|c|c|c|c|}
\hline \multirow[t]{2}{*}{ Group } & \multirow[t]{2}{*}{$N$} & \multirow{2}{*}{$\begin{array}{l}\text { Normal expression } \\
\qquad(- \text { or }+/-)\end{array}$} & \multicolumn{7}{|c|}{ Degree of COX-2 overexpression } & \multirow{2}{*}{$\begin{array}{l}\text { Value } \\
\text { of } p\end{array}$} \\
\hline & & & + & ++ & +++ & Mean & SD & Min. & Max. & \\
\hline \multirow[t]{2}{*}{ A } & 30 & 9 & 13 & 3 & 5 & 1.62 & 0.86 & 1 & 3 & \multirow[t]{2}{*}{ NS } \\
\hline & & & $61.9 \%$ & $14.3 \%$ & $23.8 \%$ & & & & & \\
\hline \multirow[t]{2}{*}{ B } & 20 & 7 & 8 & 4 & 1 & 1.46 & 0.66 & 1 & 3 & \multirow[t]{2}{*}{ NS } \\
\hline & & & $61.5 \%$ & $30.8 \%$ & $7.7 \%$ & & & & & \\
\hline \multirow[t]{2}{*}{ K } & 10 & 3 & 3 & 3 & 1 & 1.71 & 0.76 & 1 & 3 & \multirow[t]{2}{*}{ NS } \\
\hline & & & $42.9 \%$ & $42.9 \%$ & $14.2 \%$ & & & & & \\
\hline
\end{tabular}


the degree of COX-2 expression was performed after 12 months. Analysing only the presence or absence of overexpression (omitting its severity), its incidence was statistically significantly lower in patients treated with APC ablation of metaplastic mucosa (group A and B) as compared to initial values. Overexpression of COX-2 was found in 6 patients from group A (combination of APC and PPI) and 3 from group $B$ (combination of APC and LNF). The difference between group A and B was not significant (Table III). The expression of COX-2 in the control group (K) did not change after 12 months of PPI treatment. The difference between both groups treated with APC (A and $B$ ) and controls $(K)$ was statistically significant (Table III).

The degree of COX-2 expression after treatment was the subject of further analysis. Among patients from group A (APC + PPI) low overexpression (+) was found in $4(13.3 \%)$ and moderate in $2(6.7 \%)$. Those last 2 patients initially had IM (+) without dysplasia. In the follow-up evaluation, after 12 months of treatment none of the patients had high overexpression $(+++)$ of COX-2. In 24 patients (80\%) from this group expression of COX-2 was normal (Table IV).

Only 3 patients $(15 \%)$ from group B (APC + LNF) showed increased expression of COX-2 in the followup evaluation performed after 12 months. In 2 of them $(10 \%)$ the degree of overexpression was assessed as low (+) and in 1 (5\%) as moderate (++). This last patient initially had IM (-) with low-grade dysplasia in the first evaluation. None of the patients had high overexpression of COX-2 (+++) in the followup examination (Table IV).

Among controls (group K) treated for 12 months only with PPI excessive expression of COX-2 was found in 7 patients (70\%). As in the initial evaluation, high COX-2 overexpression (+++) was demonstrated in 1 patient. In the follow-up examination overexpression of COX-2 was low (+) in 4 patients and moderate

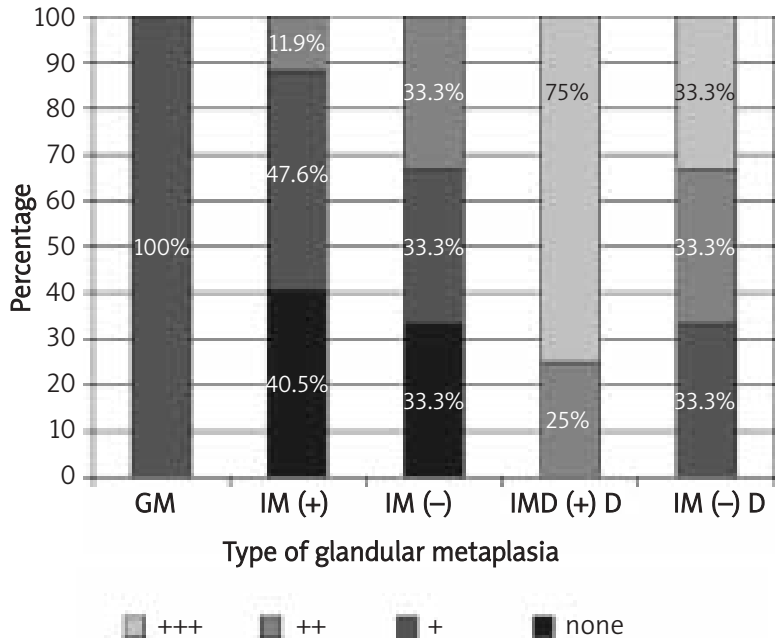

GM - gastrin metaplasia, IM (+) - complete intestinal metaplasia, IM (-) - incomplete intestinal metaplasia, IM (+) D - complete intestinal metaplasia with low-grade or moderate dysplasia, IM (-) D-incomplete intestinal metaplasia with low-grade or moderate dysplasia

Figure 2. The degree of COX-2 overexpression related to histological type of glandular metaplasia

Table III. Changes of COX-2 expression after treatment compared to baseline

\begin{tabular}{|cccccc|}
\hline Group & $N$ & When & \multicolumn{2}{c|}{ Expression of COX-2 } & Value of $p$ \\
\cline { 3 - 5 } & & & Absent & Present nn & \\
\hline A & 30 & Before & 9 & 21 & \multirow{2}{*}{$<0.001$} \\
\cline { 3 - 5 } & & After & 24 & 6 & \\
\hline B & 20 & Before & 7 & 13 & $<0.001$ \\
\cline { 3 - 5 } & & After & 17 & 3 & \\
\hline K & 10 & Before & 3 & 7 & NS \\
\cline { 3 - 5 } & & After & 3 & 7 & \\
\hline
\end{tabular}

$A: B-N S ; A: K-p<0.001 ; B: K-p<0.001$

Table IV. The degree of COX-2 expression in the follow-up examination 12 months after treatment

\begin{tabular}{|llcccc|}
\hline \multirow{2}{*}{ Group } & $N$ & Normal expression (- or + - $)$ & \multicolumn{3}{c|}{ Degree of COX-2 overexpression } \\
\cline { 4 - 6 } & & & + & ++ & +++ \\
\hline A & 30 & $24(80 \%)$ & $4(13.3 \%)$ & $2(6.7 \%)$ & 0 \\
\hline B & 20 & $17(85 \%)$ & $2(10 \%)$ & $1(5 \%)$ & $1(10 \%)$ \\
\hline K & 10 & $3(30 \%)$ & $4(40 \%)$ & $2(20 \%)$ & 0 \\
\hline
\end{tabular}


(++) in 2 patients. In 3 patients at the beginning and after completion of the study protocol expression of COX-2 was normal (Table IV).

\section{Discussion}

Identification of the factors leading to the development of BE and consequently adenocarcinoma has been the subject of research for many years. Chronic irritation of the mucosa of the distal oesophagus by reflux is crucial. It remains however unclear why some patients develop only reflux oesophagitis, while others develop Barrett's metaplasia.

A uniform diagnostic and therapeutic algorithm has not been reached yet. Various factors have been blamed for this, including variability of the clinical picture, frequent modifications of the definition of $B E$ and poorly understood pathogenesis of this disease [23]. There is however general agreement that the main goal of management is treatment of GERD [24]. The normalization of $\mathrm{pH}$ in the gastroesophageal junction is crucial and is most frequently achieved by administration of PPI. This treatment results in an excellent symptomatic response and reduction of the inflammation of the mucosa of the distal oesophagus.

Undoubtedly studies on the molecular background for the sequence metaplasia-dysplasiacarcinoma may be the key to understanding the details of the pathogenesis of BE. Defects of apoptosis appear to be particularly important in the development of dysplasia and adenocarcinoma in these patients. One of the proposed mechanisms of distorted pathways of programmed cell death is physiologically increased synthesis of the factors limiting this process. Cyclooxygenase- 2 inhibits apoptosis in vitro [25]. In the process of carcinogenesis overexpression of COX-2 interferes with regulation of metabolism of arachidonic acid. This leads to the increased production of prostaglandins, which influences the proliferation of the cells, enhances angiogenesis, reduces apoptosis, stimulates tumour growth, modulates the immune response and reduces the adhesion of the cells, leading in consequence to progression of the neoplasm [7]. Irritation of metaplastic mucosa by acidic gastric content activates mitogen-activated protein kinase (MAPK), resulting in increased inflow of proliferative signals to the cell nucleus [12]. Overexpression of this enzyme has been found in numerous gastrointestinal cancers, including oesophageal adenocarcinoma [9]. In the available literature, some evidence for the presence of increased expression of COX-2 in metaplastic mucosa in patients with BE can be found. It is believed that overexpression of this enzyme is in close correlation with the persistence of chronic inflammatory processes, which promotes carcinogenesis [26]. In this study overexpression of COX-2 was documented in most patients (Table II). A correlation between increased expression of COX-2 and the degree of dysplasia was found in the presented material (Figure 1). Similar conclusions can be found in the publication of Schirvani [10]. In his study the synergistic role of acid and bile contained in the refluxate as factors responsible for increased expression of COX-2 was highlighted.

According to the opinion of some authors, effective suppression of gastric acid secretion can lead not only to re-epithelialization of the squamous mucosa, but also to reduction of the expression of several biomarkers characteristic for the process of proliferation [27]. In this study only in one patient from the control group (K), in whom overexpression of COX-2 was not present both before and after treatment, did metaplasia disappear completely after one year of PPI administration. The highest expression in this group was observed in a patient with moderate grade dysplasia associated with complete intestinal metaplasia. In this case however, the final expression of COX-2 did not change compared to baseline after 12-month therapy with pantoprazole $80 \mathrm{mg}$ daily (Table III). It seems therefore that the use of proton pump inhibitors as a sole mode of treatment does not significantly influence the degree of expression of COX-2 in patients with Barrett' oesophagus. However, the size of the study groups and the short time of observation do not allow for definite conclusions, and further studies are needed. Perhaps combination of PPI and inhibitors of cyclooxygenase in chemoprevention of adenocarcinoma of the oesophagus may provide a beneficial effect.

Numerous studies point to the protective effect of NSAIDs - especially selective COX-2 inhibitors - in the prevention of oesophageal and colorectal cancer [14]. Studies on their application in chemoprevention of gastrointestinal cancers were discontinued due to important side-effects of rofecoxib discovered during the study for colorectal cancer prevention (Adenomatous Polyp PRevention On Vioxx - APPROVe). The risk 
of heart attack or stroke was doubled among patients taking this medication [15]. Farrow demonstrated significantly reduced risk of both adenocarcinoma and squamous cell cancer of the oesophagus in patients chronically using aspirin [28]. The multicentre programme ASPECT is currently focusing on its effect on BE and cancer.

In patients undergoing argon plasma ablation, effective eradication of metaplastic mucosa resulted in marked reduction of COX-2 expression. Initially overexpression of COX-2 was found in 21 patients (70\%) treated with the combination of APC and PPI (group A) and 13 patients (65\%) in whom APC ablation was followed by the anti-reflux procedure (group B). After 12 months increased expression of this enzyme was observed only in 6 patients of group $A$ and 3 of group B (Table III). The effect of ablative therapy supplemented by administration of pantoprazole or laparoscopic Nissen fundoplication was significantly better compared to the control group with respect to the level of expression of COX-2 (Table III).

Taking into consideration the documented role of the cellular signalling pathway involving COX-2 in carcinogenesis it might be concluded that argon plasma ablation could be a superior method in prevention of progression of Barrett's metaplasia as compared to anti-secretory treatment. The study failed to demonstrate an advantage of laparoscopic Nissen fundoplication over high doses of pantoprazole therapy as a supplementary method after APC ablation. Further studies are needed to fully document the value of COX-2 expression as a prognostic factor in the development of more advanced forms of BE and adenocarcinoma. It seems however that the level of expression of COX-2 correlates well with the histopathological findings in BE, particularly the level of dysplasia. These conclusions are supported by the documented relation of different types of metaplasia with varying degrees of overexpression of COX-2.

\section{Conclusions}

1. Overexpression of COX-2 can be documented in most patients with $\mathrm{BE}$, particularly those with associated dysplasia.

2. In most patients treatment results correlate with the degree of overexpression of COX-2, which suggests the value of this parameter as a possible biomarker of the development of oesophageal adenocarcinoma related Barrett's metaplasia.

\section{References}

1. Sharma P, Morales TG, Sampliner RE. Short segment Barrett's esophagus-the need for standardization of the definition and of endoscopic criteria. Am J Gastroenterol 1998; 93: 1033-6.

2. Caygill CP, Watson A, Reed PI, et al. UK National Barrett's Oesophagus Registry (UKBOR) and the 27 Participating Centres, Characteristics and regional variations of patients with Barrett's oesophagus in the UK. Eur J Gastroenterol Hepatol. 2003; 15; 1217-22.

3. Cameron AJ, Lomboy CT, Pera M, et al. Adenocarcinoma of the esophagogastric junction and Barrett's esophagus, Gastroenterology 1995; 109: 1541-6.

4. Konturek SJ, Konturek PC, Brzozowski T, Bubenik GA. Role of melatonin in upper gastrointestinal tract. J Physiol Pharmacol 2007; 58 Suppl 6: 23-52.

5. Konturek SJ, Zayachkivska O, Havryluk XO, et al. Protective influence of melatonin against acute esophageal lesions involves prostaglandins, nitric oxide and sensory nerves. J Physiol Pharmacol 2007; 58: 361-77.

6. Nishijima K, Miwa K, Miyashita T, et al. Impact of the biliary diversion procedure on carcinogenesis in Barrett's esophagus surgically induced by duodenoesophageal reflux in rats. Ann Surg 2004; 240: 57-67.

7. Majka J, Szlachcic A, Brzozowski T, et al. Funkcjonalne znaczenie wzajemnej interakcji aktywności cyklooksygenazy-2, nabłonkowego czynnika wzrostu (EGF) i jego receptora w patogenezie przewlekłego zapalenia przełyku w świetle badań klinicznych i doświadczalnych. Gastroeneterol Pol 2009; 16: 45-9.

8. Reid BJ, Blount PL, Rabinovitch PS. Biomarkers in Barrett's esophagus. Gastrointest Endosc Clin N Am 2003; 13: 369-97.

9. Konturek PC, Kania J, Burnat G, et al. Prostaglandins as mediators of COX-2 derived carcinogenesis in gastrointestinal tract. J Physiol Pharmacol 2005; 56 Suppl 5: 57-73.

10. Shirvani VN, Ouatu-Lascar R, Kaur BS, et al. Cyclooxygenase 2 expression in Barrett's esophagus and adenocarcinoma: ex vivo induction by bile salts and acid exposure. Gastroenterology 2000; 118: 487-96.

11. Konturek PC, Burnat G, Hahn EG. Inhibition of Barret's adenocarcinoma cell growth by simvastatin: involvement of COX-2 and apoptosis-related proteins. J Physiol Pharmacol 2007; 58 Suppl 3: 141-8.

12. Souza RF, Shewmake K, Terada LS, et al. Acid exposure activates the mitogen-activated protein kinase pathways in Barrett's esophagus. Gastroenterology 2002; 122: 299-307.

13. Konturek PC, Kania J, Burnat G, Hahn EG. NO-releasing aspirin exerts stronger growth inhibitory effect on Barrett's adenocarcinoma cells than traditional aspirin. J Physiol Pharmacol 2006; 57 Suppl 12: 15-24.

14. Hartwich A, Konturek S, Pierzchalski P, et al. Molecular basis of colorectal cancer - role of gastrin and cyclooxygenase-2. Med Sci Monit 2001; 7: 1171-81.

15. Bresalier RS, Sandler RS, Quan H, et al. Cardiovascular events associated with rofecoxib in a colorectal adenoma chemoprevention trial. N Engl J Med 2006; 355: 221.

16. Wilson KT, Fu S, Ramanujam KS, et al. Increased expression of inducible nitric oxide synthase and cyclooxygenase-2 in Barrett's 
esophagus and associated adenocarcinomas. Cancer Res 1998; 58: 2929-34.

17. Morris CD, Armstrong GR, Bigley G, et al. Cyclooxygenase-2 expression in the Barrett's metaplasia-dysplasia-adenocarcinoma sequence. Am J Gastroenterol 2001; 96: 990-6.

18. Buskens CJ, Van Rees BP, Sivula A, et al. Prognostic significance of elevated cyclooxygenase 2 expression in patients with adenocarcinoma of the esophagus. Gastroenterology 2002; 122: 1800-7.

19. Wróblewski T, Skalski M, Ziarkiewicz-Wróblewska B, et al. Postępy w leczeniu chirurgicznym choroby refluksowej. Wideochirurgia i inne techniki małoinwazyjne 2006; 1: 121-4.

20. Wróblewski T, Grodzicki M, Ziarkiewicz-Wróblewska B, et al. Aspekty techniczne i wyniki laparoskopowej fundoplikacji sposobem Toupet w leczeniu zaawansowanej postaci refluksu żołądkowo-przełykowego (GERD). Wideochirurgia i inne techniki małoinwazyjne 2006; 1: 6-9.

21. Migaczewski M, Budzyński A, Rembiasz K, et al. Quality of life of patients with gastroesophageal reflux disease after laparoscopic Nissen fundoplication. Videosurgery and other miniinvasive techniques 2008; 3: 119-25.

22. Migaczewski M, Budzyński A, Rembiasz K. Argon plasma coagulation (APC) for treatment of Barrett's oesophagus. Videosurgery and other miniinvasive techniques 2009; 4: 102-9.

23. Wang KK, Sampliner RE. Updated Guidelines 2008 for the Diagnosis, Surveillance and Therapy of Barrett's Esophagus. Am J Gastroenterol 2008; 103: 788-97.

24. Sampliner RE; Practice Parameters Committee of the American College of Gastroenterology. Updated guidelines for the diagnosis, surveillance, and therapy of Barrett's esophagus. Am J Gastroenterol 2002; 97: 1888-95.

25. Tsujii M, DuBois RN. Alterations in cellular adhesion and apoptosis in epithelial cells overexpressing prostaglandin endoperoxide synthase 2. Cell 1995; 83: 493-501.

26. Cheong E, Igali L, Harvey I, et al. Cyclo-oxygenase-2 expression in Barrett's oesophageal carcinogenesis: an immunohistochemical study. Aliment Pharmacol Ther 2003; 17: 379-86.

27. Ouatu-Lascar R, Fitzgerald RC, Triadafilopoulos G. Differentiation and proliferation in Barrett's esophagus and the effects of acid suppression. Gastroenterology 1999; 117: 327-35.

28. Zagorowicz E, Jankowski J. Molecular changes in the progression of Barrett's oesophagus. Postgrad Med J 2007; 83: 529-35. 